\title{
SOR JUANA INES DE LA CRUZ: \\ OBEDIENCIA Y AUTORIDAD EN SU ENTORNO RELIGIOSO
}

POR

\author{
Asunción Lavrin \\ Arizona State University, Tempe
}

Tras casi trescientos años de su muerte, la figura de Sor Juana Inés de la Cruz se nos muestra aún elusiva y evanescente ante la historia. La búsqueda de huellas históricas fidedignas sobre las cuales apoyar nuevas inferencias no ha rendido nuevos frutos. ${ }^{1}$ Sor Juana se nos dió en su escritura, de la cual eminentes críticos se siguen ocupando con pasión, pero con los historiadores fue más parca, guardando en su silencio las claves que nos darían una mejor comprensión de su vida. En su reciente análisis sobre dos biografias de Sor Juana - las de Dorothy Schons y la de Octavio Paz-Georgina Sabat Rivers nos muestra cómo dos eminentes estudiosos de esa vida se enfrentaron y resolvieron a su modo la desafiante tarea de recrearla con la parquedad de hechos constatables y los problemas suscitados por tal situación. ${ }^{2}$

Para el historiador el objetivo más asequible es llegar a conocer mejor la realidad dentro de la cual vivió Sor Juana, hurgando en archivos y sacando a la luz todo lo que pueda acercarnos al vivir, pensar y sentir de sus contemporáneos. Este trabajo es elíptico y no me salva de tener que hacer interpretaciones, pero creo que mi contribución servirá

\footnotetext{
'La búsqueda de materiales en los archivos de México y España dió a conocer muchos datos sobre la familia de Sor Juana y su nacimiento. El más reciente hallazgo es la llamada carta de Monterrey. No se han encontrado nuevos documentos que revelen más datos históricos sobre ella. Véanse, Aureliano Tapia Méndezx, ed. Carta espiritual de Sor Juana Inés de la Cruz a su confesor: Autodefensa espiritual (Monterrey: Impresora Monterrey, S.A. 1986); Guillermo Ramírez España, La familia de Sor Juana Inés de la Cruz: Documentos inéditos (México: Imprenta Universitaria, 1947), 12-21. La Carta de Monterrey ha sido traducida al inglés por Nina M. Scott, "If You Are Not Pleased to Favor Me, Put Me Out of Your Mind ..." Gender and Authority in Sor Juana Inés de la Cruz, Women's Studies Forum (11:5): 429-438.

${ }^{2}$ Georgina Sabat-Rivers, "Biografias: Sor Juana vista por Dorothy Schons y Octavio Paz" en Georgina Sabat-Rivers, Sor Juana Inés de la Cruz y otros poetas Barrocos de la Colonia (Barcelona: PPU, 1992), 327-339. Schons novelizó ayudándose de escasos datos históricos, pero logró una aproximación empatética muy notable. Paz cobija su trabajo bajo un más amplio techo de estudios académicos presentándonos una obra mucho más amplia aunque también teñida por sus interpretaciones. Todos los que nos acercamos a esta polifacética escritora debemos tomar el vuelo de la interpretación cuando faltan datos y, en consecuencia, aceptar que hay espacio para otras interpretaciones.
} 
para hacer más seguro el terreno que pisamos. En un trabajo de 1982 traté de enmarcar a Sor Juana dentro del conjunto de escritoras conventuales y subrayar las diferencias entre ella y sus compañeras de claustro. En otro más reciente y aún inédito, me apoyé en el conocimiento de la mujer y las relaciones de género de mitad del siglo XVII para saber cuán común eran algunos rasgos de su vivencia como mujer con los de otras mujeres de su época. ${ }^{3}$ En éste, deseo explorar el tema de la obediencia y la desobediencia religiosa en las relaciones entre prelados, religiosas, y autoridades reales con ejemplos mayormente (aunque no exclusivamente) del siglo diecisiete. Estos datos serán utilizados para revisar un aspecto crítico de la vida de Sor Juana y de todas las monjas: el deber de la obediencia a la autoridad eclesiástica, contrapuesto a la urgencia de reafirmar la existencia propia a través de la expresión intelectual y espiritual.

Para plantear propiamente la tensión existente entre estos polos conceptuales debemos tener en cuenta que la misma envolvió tanto a los prelados como a las monjas. Las religiosas vieron el binomio autoridad-obediencia como relación personal con sus confesores y como comunidad frente a órdenes de sus superiores religiosos o los representantes de la autoridad civil, actuando en nombre de los intereses del estado. Por su parte, los prelados asumían amplio dominio sobre sus hijas espirituales, pero el mismo implicaba la responsabilidad de guiarlas hacia el objetivo claramente definido de la salvación de sus almas y no un mero ejercicio de poder. El prelado también era miembro de una jerarquía político-social que le hacía responsable de los intereses de su corporación frente a otras entidades y autoridades. Esta red de obligaciones llevaron a obispos, arzobispos, y ministros provinciales de las órdenes religiosas, a numerosos choques entre sí, y a plantearse problemas de autoridad, obediencia y desobediencia frente a la comunidad de las monjas y la corona.

La importancia del estudio del entorno religioso de Sor Juana reside para mí en tratar de comprender su especial relación con los hombres que tuvieron una influencia decisiva sobre su vida. Creo que es posible y deseable replantear el muy debatido tema de la relación de Sor Juana con el obispo Manuel Fernández de Santa Cruz (y con su confesor Antonio Núñez) si lo hacemos a través del prisma de los votos religiosos y el significado de los conceptos de obediencia y autoridad. El estudio de la escritura religiosa de Sor Juana y su posible vena teológica es bien reciente, y aún cabe preguntarse ¿qué sabemos de su vida como religiosa o de sus relaciones con aquéllos que la dirigieron? ${ }^{4}$ Poco o nada

\footnotetext{
3 "Sor Juana Inés de la Cruz: A Woman Among Women", Paper given at Pomona College, March 3-4, 1989, Conference on "Sor Juan Inés de la Cruz: Portraits and Perspectives"; "Unlike Sor Juana? The Model Run in the Religious Literature of Colonial Mexico", University of Dayton Review, 16:2 (Spring 1983), 75-92. Reissued in Stephanie Merrim ed., Towards a Feminist Understanding of Sor Juana Inés de la Cruz (Detroit: Wayne State University Press, 1990), 61-85.

${ }^{4}$ George H. Tavard, Juana Inés de la Cruz and the Theology of Beauty (Notre Dame, Indiana: University of Notre Dame Press, 1991); Georgina Sabat-Rivers, "Ejercicios de la Encarnación: sobre la imagen de María y la decisión final de Sor Juana" en Sabat-Rivers, Sor Juana Inés de la Cruz y otros poetas, 257-82; Amanda Powell, "Women's Reasons: Feminism and Spirituality in Old and New Spain" Studia Mystica 15:2-3 (Summer-Fall 1992): 58-69; Josefina Muriel, "Sor Juana Inés de la Cruz y los escritos del Padre Antonio Núnez" en Sara Poot Herrera, ed. Y Diversa de mi misma entre vuestra plumas ando: Homenaje internacional a Sor Juana Inés de la Cruz (Mexico: El Colegio de Mexico, 1993), 71-84.
} 
hasta el descubrimiento de la llamada Carta de Monterrey y, desde luego la respuesta al obispo Fernández de Santa Cruz. Lo estrictamente histórico, no la escritura de carácter religioso, es bastante poco.

Los prelados del siglo XVII, y aun los del XVIII, traían de España una visión contrarreformista de la vida religiosa que encontró una realidad bien diferente en el Nuevo Mundo. Su tarea fue la de hacer una transferencia cultural-religiosa y guiar a su nuevo rebaño dentro de la ortodoxia católica aunque sin dejar de tomar en cuenta la idoneidad americana. ¿Lo lograron o no? No podemos dar aún una respuesta cabal a esta pregunta. Necesitamos saber mucho más sobre los escritos pastorales y la práctica de dirección espiritual que ejercieron con sus hijas de religión los arzobispos y obispos del siglo diecisiete para comenzar a desentrañar la espiritualidad y la práctica de los conceptos de autoridad episcopal y obediencia religiosa del mundo barroco novohispano. Pero, juzgando por los datos ya en nuestras manos, hubo muchos escollos en el camino de perfección causados por el desfase entre lo peninsular y lo americano que, unido a los problemas personales e institucionales arriba citados, hacen del estudio de la vida religiosa un quehacer lleno de sorpresas. $^{5}$

Propongo adentrarme en el tema del contexto eclesiástico en el cual vivió Sor Juana utilizando mis investigaciones en archivos españoles y mexicanos, y utilizando la literatura religiosa de la época para sostener mi versión de algunos momentos claves en la vida de Sor Juana. Es importante comenzar recordando el significado de uno de los cuatro votos esenciales de la vida monástica, el de la obediencia. Antonio Núñez de Miranda, S. J. la definió como la renuncia a la propia voluntad para sujetarse a la de sus prelados; era pecado mortal cuando no se cumplía a cabalidad. Tanto para este jesuita como para otros teólogos contemporáneos de Sor Juana, los prelados (se incluyen las abadesas en su función de máxima autoridad dentro del convento) ejercían su autoridad en nombre de Jesús. La religiosa era súbdita obligada a hacer pronta y alegremente lo que le mandaren, juzgándolo por mejor que su propia opinión. Al confesor se le debía obedecer al pie de la letra. ${ }^{6}$

Las cartas pastorales y las revisiones de las reglas conventuales que dieron los prelados novohispanos a sus hijas espirituales les recordaban sus deberes con toda puntualidad, pues la continua vigilancia era la clave del éxito en la vida espiritual. En las reglas dadas a las religiosas del convento de San Lorenzo de México por el arzobispo Juan de Ortega y Montañés (1700-08) se ordenaba dar obediencia y reverencia al arzobispo y las autoridades

\footnotetext{
${ }^{5}$ Marie-Cécile Bénassy-Berling, Humanisme et Religion chez Sor Juana Inés de la Cruz: la femme et la culture au XVIIè Siècle (Paris: Publications de la Sorbonne, 1982); José L. Sánchez Lora, Mujeres, conventos y formas de la religiosidad barroca (Madrid: Fundación Universitaria española, 1988); Electa Arenal y Georgina Sabat Rivers, eds. Literatura conventual femenina: Sor Marcela de San Félix, hija de Lope de Vega. Obra Completa (Madrid: PPU, 1988); Manuel Ramos Medina, Imagen de santidad en un mundo profano (México: Universidad Iberoamericana, 1990); Clara García Ayluardo y Manuel Ramos, coord. Manifestaciones religiosas en el mundo colonial americano, Vol. 1 (México, 1993); Kathleen Myers, Word From New Spain: The Spiritual Autobiography of Madre María de San José (1656-1719) (Liverpool: University of Liverpool Press, 1993).

${ }^{6}$ Antonio Núñez, Plática doctrinal ... en la profesión de una Señora religiosa del convento de San Lorenzo (México, 1710), 6; Cartilla de la doctrina religiosa (México, 1708), 12.
} 
diocesanas en lo tocante a la comunidad y en lo particular de cada religiosa. El arzobispo era padre, pastor de sus almas y protector, en quien debían ver la fuente de toda seguridad y confianza respecto a sus necesidades espirituales y temporales. ${ }^{7}$ El arzobispo José Lanciego y Eguilaz (1714-28) recomendó a sus hijas espirituales la Cartilla del Padre Antonio Núñez en su primera Carta Pastoral a las religiosas de México, evidencia del prestigio que retuvo el bien conocido jesuíta aún después de su muerte. Entre los ejercicios espirituales que les recomendó para fortalecer su espíritu religioso recomendaba la meditación de la pasión de Cristo, que resultó de la completa obediencia que Cristo prestó a la voluntad de Dios. "Considera como el Eterno Padre puso a su hijo a morir en la cruz y la docilidad del hijo aceptándolo". ${ }^{8}$ La obediencia se hermanaba con la humildad en la literatura hagiográfica. José Martínez de la Parra, explicaba sobre una religiosa, que "vale decir es humilde, luego es obediente; es obediente, luego es humilde". 9 Ambas eran virtudes, pero la obediencia era, además, obligación. Explicando las reglas de las clarisas, Fray Nicolás Quiñones diferenciaba entre la obediencia de necesidad, que era la que obligaba a obedecer todo lo contenido en las Constituciones de la Regla, mientras que la obediencia de perfección, era todo lo que se hacía por obediencia a Dios, al alma y a la Regla. ${ }^{10}$

La obediencia tenía sus cotos. No negaba la soberanía del ser, la autoridad que sobre sí ejercía todo individuo en plena facultad de su libre albedrío. Todas las personas conservan la facultad, concedida por Dios, de la libertad de tomar decisiones, y la decisión de obedecer es, asimismo, propia e irrevocablemente individual. Cuando una orden iba en contra de lo establecido por las reglas o llevaba a un pecado capital, se podía desobedecer. ${ }^{11}$ Esta

7 Juan de Ortega y Montañés, Constituciones de las religiosas gerónimas del convento de San Lorenzo de la ciudad de México (México, 1707), 34.

${ }^{8}$ Joseph Lanciego y Eguilaz, Carta pastoral a sus amadas hijas las religiosas de toda su filiación (México, 1716), 17. La interpretación del precepto de obediencia no varió en nada a través del tiempo. El arzobispo Alonso Núnez de Haro y Peralta (1772-1800) recomendaba la renuncia de la voluntad propia como parte del sacrificio que se hacía a Dios. En un encomio de la virtud de la humildad, compañera de la obediencia, recomendaba a sus súbditas pensar del modo siguiente: "Cuanto yo más me abata; cuanto más despreciada me vea, cuanto menos busque los aplausos que el mundo estima, tanto seré más semejante a Jesús mi salvador, mi Rey supremo, mi bien, mi adorado Esposo. Yo amaré la pobreza y sufriré, no sólo con paciencia, sino con alegría las injurias, el olvido y el desprecio. De este modo me veré libre de mi amor propio y vanidad, que me han obligado a hacer y decir tantas cosas, muy ajenas de mi profesión". Nótese que la base espiritual de la renuncia a las cosas del mundo no ha variado un siglo después que Manuel Fernández de Santa Cruz recomendó a Sor Juana zafarse de los "intereses rateros" del mundo. Véase, Alonso Núnez de Haro y Peralta, Sermones panegíricos y pláticas espirituales 2 Vol. (Madrid, 1807), 325.

${ }^{9}$ Gómez de la Parra, Fundación y primer siglo. Crónica del primer convento de carmelitas descalzas en Puebla, 1604-1704 (México: Universidad Iberoamericana, 1992), 215; Manuel Ramos Medina, Imagen de santidad en un mundo profano (México: Universidad Iberoamericana, 1990), 92-105.

${ }^{10} \mathrm{Fr}$. Nicolás Quinones, Explicación de la Primera regla de la Esclarecida Madre Santa Clara de Asís (México, 1736), 25. Esta obra fue escrita para las monjas indígenas del convento de Corpus Christi en México.

"En 1803, el arzobispo de México Francisco Javier Lizana y Beaumont (1802-11), explicaba que la única forma válida de apartarse del precepto de obediencia era cuando en obedecer se ponía a riesgo los otros votos. La obediencia debía de ser de juicio, de voluntad y obra, como la de la oveja que oía 
teóricamente pequeña puerta de escape la utilizaron con generosidad tanto súbditas como prelados novohispanos tanto cuando las circunstancias lo requirieron, como cuando no eran ni tan claras ni tan autoevidentes. Precisamente porque ni la autoridad se ejerció sin desafíos, ni la obediencia se dió incondicionalmente, existieron muchas tensiones administrativas y personales dentro del estado religioso. Hubo modalidades de desobediencia dentro de los parámetros de la obediencia que permitieron a prelados y a súbditas eludirse entre sí o eludir a sus superiores y seguir un curso de acción propio. Aunque aún no está perfectamente calibrado, es el juego entre los límites de la obediencia y la autoridad lo que determina el sesgo de los acontecimientos históricos.

Veamos cómo podemos poner estos conceptos de modo más pragmático con algunos ejemplos del choque inevitable de voluntades que nació de la confrontación entre autoridad y obediencia. Los informes rendidos por los obispos y arzobispos novohispanos al Consejo de Indias en España hablaron con frases encomiásticas y generales de la santidad y observancia de los conventos femeninos, ofreciendo una visión superficial que ocultaba importantes luchas internas y que seguían sinuosos cursos subterráneos bajo una aparente calma diocesana. Por ejemplo, las carmelitas descalzas de México, establecidas en 1616, comenzaron a hacer gestiones a mediados de siglo para lograr su libertad de la autoridad diocesana y ponerse bajo la de la propia orden. Se sentían más cómodas y cumpliendo mejor las exigencias de su regla si la dirigían y confesaban carmelitas descalzos en vez de los clérigos diocesanos asignados por los obispos. Entre 1652 y 1659 las religiosas se quejaron en varias cartas al Consejo de Indias y al rey de España de la falta de atención que recibían de los clérigos confesores, a quienes juzgaban inapropiados para dirigirlas en oración y regla. Esta opinión no cayó bien en el arzobispo Mateo Saga de Bugueiro (1655-1663), un abierto protector de la orden capuchina, que trajo de España a Nueva España, y según la opinión del arzobispo historiador Francisco Antonio de Lorenzana (1766-1772), "acérrimo defensor de su jurisdicción eclesiástica". ${ }^{12}$

La religiosa carmelita Sor María de Santa Inés, mantuvo una relación amistosa con la virreina, esposa del duque de Alburquerque (1653-1660), y en varias cartas fechadas a 19 de noviembre, 26 de noviembre, y 6 de diciembre de 1658, le explicó como habían sido intimidadas por el arzobispo a abandonar su petición de ser puestas bajo la administración de la Orden del Carmelo, bajo el concepto de que pecaban al protestar. Pedía Sor María su intercesión a la virreina como "amparo y consuelo de este convento". El 30 de marzo de 1657 se dirigieron las monjas al virrey, agradeciéndole su apoyo, y expresando que "debemos la vida a su piedad" doliéndose de "ver imputada nuestra humildad y rendimiento con la nota de inobedientes a Ntro Rmo prelado a cuyos pies pedimos tuviese piedad de nuestra flaqueza y templase sus mandatos ..."13 No hay rebelión abierta contra el prelado, sino una estrategia de búsqueda del apoyo de aliados poderosos, la virreina y el virrey. Sin traspasar los límites espirituales de obediencia que debían al prelado, las religiosas usaban

a su pastor. Ver, Carta pastoral a las RR.MM. superioras y súbditas del Arzobispado de México (México, 1803), 19-22.

${ }_{12}$ Francisco Sosa, El episcopado mexicano: Biografia de los Ilmos, Señores Arzobispos de México 2 Vol. (México: Editorial Jus 1962), 1:251.

${ }^{13}$ AGI, México, 30, No 10. 
argumentos teológicamente válidos para lograr un cambio de su situación. El arzobispo se negó a aceptar toda interferencia con su voluntad, expresando que hasta Roma iría antes de ceder a la pretendida libertad de las carmelitas. La clave de esta situación se encuentra en el feudo político entre el arzobispo y el virrey, que se inició desde la llegada del primero al virreinato. Las carmelitas aprovecharon hasta la última gota su amistad con el virrey, y en 1659 se seguían quejando de las "asperezas y desatenciones" del obispo. ${ }^{14}$

En 1661 las monjas se descargaron espiritualmente ante miembros de la Inquisición, a quien llamaron para aclarar su situación y las acusaciones del arzobispo Saga de Bugueiro. El arzobispo no se había presentado al convento a llevar a cabo la elección canónica de abadesa y oficialas del convento. También les había prohibido comunicarse con persona alguna, pero las religiosas siguieron su conciencia en vez de la orden arzobispal e hicieron relación de las intempestivas visitas de Saga de Bugueiro al convento. Sor María, la corresponsal de la virreina, declaró que el arzobispo se había portado "muy colérico y destemplado" durante una visita. En esa ocasión penetró en la clausura con sus criados, las obligó a levantarse los velos y descubrirse el rostro para darles una plática en las cual las había acusado de pecar mortalmente, las llamó "ilusas bachilleras" en nada dignas de su santa madre y les dijo "que aunque viniesen diez cédulas nunca habia de venir en ello ..."15 El obispo las acusaba de que era "temeraria presunción y contra la santa fé decir que este u otro género de persona por ser clérigos de orden religiosa tienen comunicado de Dios especial conocimiento", lo que podía ponerlas en entredicho con la Inquisición. Si el objetivo del arzobispo fue atemorizar a las religiosas, su presión no surtió efecto. Los cargos pudieran haber servido para crear incertidumbre en la comunidad, como la hubo, pero había poca base para ninguna condena ya que las monjas no hicieron tal aseveración. ¿Sería éste el tipo de investigación inquisitorial a que se refirió Sor Juana en su bien conocida Respuesta unos treinta años después?

En 1663 Saga de Bugueiro fue trasladado a Cartagena, pero su ausencia no resolvió el problema jurisdiccional. Tanto Felipe IV como el Consejo de Indias oyeron a las carmelitas de México con simpatía y pidieron al Papa su consentimiento para el cambio de jurisdicción, que fue concedida siempre y cuando el arzobispo de México consientiera también. ${ }^{16}$ Sin embargo, al igual que Saga de Bugueiro en su prelacía, el nuevo arzobispo de México, Fray Payo de Rivera (1668-1681), negó la petición carmelita y no concedió ni un palmo, aduciendo su autoridad arzobispal sobre estas religiosas y la obediencia que le debían. La aprobación de semejante cambio - arguyó-incitaría a las carmelitas de Puebla a pedir lo mismo para ellas. Un cambio administrativo podría causar un grave precedente para que otros conventos rechazaran a sus confesores y prelados. ${ }^{17}$ Este debate continuó

${ }^{14}$ J. I Israel, Race, Class and Politics in Colonial Mexico, 16109-16670 (Oxford: Oxford University Press, 1975) 257-59.

${ }^{15}$ AGN, Inquisición, 581, exp. 1 (1661). Usualmente las carmelitas descalzas mantenían los velos sobre los rostros durante cualquier comunicación con persona alguna fuera de la comunidad, y el arzobispo no era una excepción. Sin embargo, el arzobispo podía ordenarles se levantaran el velo para ejercer su autoridad de prelado y de hombre. Hay mucho simbolismo sexual en esta acción.

${ }^{16}$ AGI, México, 38, No. 71; Manuel Ramos Medina.

${ }^{17}$ AGI, México, legs 306, 330, 338. 
hasta el episcopado de José Lanciego y Eguilaz (1714-1728), y en ningún momento ni el apoyo del Papa, ni el del Rey, ni el del Consejo de Indias, logró mover la firme decisión de los arzobispos de México de mantener a las carmelitas bajo su sujeción espiritual y temporal. Las monjas se tuvieron que rendir a la autoridad episcopal, que obtuvo una victoria espiritual al mantener su inexpugnabilidad frente a las máximas autoridades civiles y religiosas.

Otra fuente de fricción entre autoridad y obediencia desde las primeras décadas del siglo XVII fue la observancia de las reglas en cuanto al número de criadas y seglares de todas las edades alojadas en los conventos, la tela y hechura de los hábitos, y el recibo de visitas en los locutorios, hechos que en su opinión "relajaban" la observancia de la disciplina religiosa, tanto material como espiritualmente. Por más de un siglo y medio se dieron patentes y órdenes de España a México, y desde las sedes episcopales y de regulares, sobre la necesidad de reformar tales costumbres. Las monjas mexicanas fueron recalcitrantes en cuanto a defender su interpretación de las reglas y mantener tanto criadas como educandas y huérfanas en los claustros.

Durante su prelacía en Puebla, Juan de Palafox y Mendoza (1640-1655), en concesión pragmática a la realidad que encontró en su diócesis, concluyó que si en los conventos de las Indias tenían las monjas muchas criadas, era también muy "dificultoso remediar este abuso sin grave escándalo, y así será mejor guiarlo de la manera que aproveche, ya que no puede quitarse, es bien que esté advertido ...", o sea bien regulado. ${ }^{18}$ Por otra parte, otros prelados llegaron de España con una intolerancia respecto al asunto que creó fricciones con sus hijas espirituales al resistir éstas la disciplina que se les quería imponer. En 1667 las monjas franciscanas de México y las de Querétaro se hallaban enfrascadas en una lucha legal contra su propio prelado, Fr. Hernando de la Rúa, quien estaba empeñado en cortar el número de criadas en los conventos. Ese año se reiteraron las órdenes sobre la observancia dada por el Comisario General de Indias en España en 1639, entre las cuales estaba la reducción del número de seglares de toda categoría en los conventos. Santa Clara de Querétaro elevó un memorial de protesta al Rey en el cual argüían haber profesado bajo el entendimiento de que tendrían ayuda de sirvientas y que las niñas no iban contra la regla. ${ }^{19}$

Ese mismo año los conventos franciscanos de San Juan de la Penitencia y Santa Isabel, elevaron recursos dirigidos al Comisario General de Indias y al Rey, defendiendo la práctica de tener criadas, porque era uso y costumbre de la tierra que tenían desde su fundación, ochenta años atrás. Cualquier cambio en la observancia interior y el régimen de vida debía ajustarse a "la calidad de la tierra y costumbres". Las monjas de Santa Isabel se quejaban de que el Comisario Provincial les había prohibido vestir lienzo, usar chocolate y tener niñas para su educación en el convento, y les había ordenado expeler todas las criadas. Si su observancia había sido aprobada por muchos y muy santos varones, ¿podría de La Rúa presumir que era más santo que otros? El solapado comentario iba dirigido a

\footnotetext{
18 Juan de Palafox y Mendoza, Bishop of Puebla. Obras del Ilustrísimo, Excelentíssimo, y Venerable Siervo de Dios. Tomo III, Part 1. Direcciones para los señores obispos (Madrid: Imprenta de Gabriel Ramírez, 1752), 46.

${ }^{19}$ Biblioteca Nacional de México, Fondo Franciscano, Caja 75, Leg 1257, fols. 12-22. De aquí en adelante citado como BN.
} 
restarle autoridad. La Rúa, sin embargo, no era amigo de ceder autoridad, y simplemente excomunicó a las protestantes, comenzando las gestiones para quitarles sus oficios dentro del convento.

Este escandaloso proceso envolvió al virrey marqués de Mancera (1664-1674), quien procuró ser intermediario entre las comunidades religiosas, su Prelado, y la Audiencia. Poniéndose de parte de las monjas, ordenó al Comisario que levantara la excomunión. La Rúa pretendió no obedecer la orden de la Audiencia, acusando a las monjas de "contumaz inobediencia", en la "moderación monástica necesaria en estas partes". Obviamente había una subyacente conciencia de diferencia entre la observancia peninsular y la que se seguía en "estos reynos", y los prelados españoles pretendían borrarla. Hay detrás de todo el proceso una vena de muy incipiente criollismo que no se explotó abiertamente por ninguna de las partes, aunque su presencia es perceptible.

El prelado levantó la excomunión, pero la última palabra llegó de España. La intervención de toda la cúspide virreinal implicaba una inmiscución del poder secular en asuntos eclesiásticos que no pasó desapercibida. La corona reprendió a la Audiencia por tomarse atribuciones más allá de su propio fuero y dejó en libertad al prelado para dirijir su rebaño ${ }^{20} \mathrm{La}$ escisión entre regla y observancia, y prelados y súbditas, siguió abierta. En 1673 Payo de Rivera ofreció obedecer la orden real de no dejar que el número de criadas en el convento de Santa Clara de Querétaro se mudara en nada, ya que las monjas habían acudido directamente al Papa, saltando por encima del arzobispo y del Consejo Real para obtener ratificación de Su Santidad sobre el número de criadas que argüían debían tener. ${ }^{21}$

Un siglo más tarde la reglamentación de la observancia dentro del claustro, llamada "vida común", desató uno de la más penosos confrontamientos entre monjas y autoridades eclesiásticas, especialmente en Puebla. Trataba la prelacía novohispana de hacer la observancia más rígida y parecida a la vida capuchina o de religiosas descalzas. Entre 1770 y 1775 las monjas elevaron cartas y autos legales al Consejo de Indias, negándose a aceptar cambios en su estilo de vida y provocando numerosos incidentes de carácter personal con sus prelados en una verdadera ola de resistencia. En una de las muchas ocasiones en que las monjas se expresaron personalemente contra la "vida común", la abadesa del convento de Santa Catarina de México, Sor María de Santa Teresa, declaró no poder seguir la observancia, que había comenzado por obedecer a su prelado, Fr. José Jorge Alfaro y Azevedo. La había experimentado por más de un mes "y hallo en mi conciencia no poder seguirla por ir en detrimento de mi salud espiritual y corporal". ${ }^{22}$

Ni Hernando de la Rúa, ni Palafox, ni Manuel Fernández de Santa Cruz, ni Francisco Aguiar y Seijas, ni Antonio Núñez, deseaban ver la relajación de la vida temporal y espiritual de los conventos de monjas, pero algunos de ellos comprendieron las variantes en la

${ }^{20}$ AGI, Escribanía de Cámara, leg. 175A.

${ }^{21}$ AGI, México, Leg. 306.

${ }_{22}$ AGI, México, Leg 2752; Francisco Fabián y Fuero, Colección de providencias dadas a fin de establecer la santa vida común, en Colección de providencias diocesanas (Puebla, 1770); AGN, Bienes Nacionales, leg. 77; Miguel A. Álvarez, a las esposas de Jesu-Christo ... (Antequera del Valle de Oaxaca, 1770); Nuria Salazar de Garza, La vida común en los conventos de monjas de la ciudad de Puebla (Puebla: Secretaría de Cultura, 1990). 
observancia americana, aflojando las reglas casuísticamente en vez de sostener un confrontamiento. ${ }^{23}$ Sería deseable establecer con nitidez qué grado de tolerancia e intolerancia mostraron los prelados respecto a sus súbditas, y qué grados de obediencia y desobediencia eran permisibles a las religiosas dentro de los parámetros de ese voto. Esta pregunta se podrá contestar cuando hayamos profundizado aún más en nuestras fuentes de información histórica y literaria. Por el momento se puede afirmar que a pesar de la la visión idealizada que proyectan de sus sujetos las muestras hagiográficas de los siglos XVII y XVIII, la obediencia fue un asunto de conciencia que se resolvió primeramente a nivel personal. De aquí pasaba a ser un proyecto comunitario que requería la cooperación de todas y cada una de las religiosas en armonía con sus superiores. Todos los actores históricos sabían que la latitud de la desobediencia tenía que ser juzgada dentro de cada situación, estudiándose las causas que podían llevar a apartarse de la norma.

Sin embargo, no deben considerarse los incidentes de desacato a la autoridad como la única tónica para juzgar la vida conventual. El confrontamiento con un superior no eclipsaba la vida espiritual de las monjas. Si la contradicción o la rebeldía iba dirigida hacia la estructura de poder dentro de la Iglesia, podían las religiosas recurrir a sus confesores para desahogar sus dudas sobre la observacia y el camino de perfección. Si el desafecto era contra el confesor, tenían la libertad de escoger otro. ${ }^{24}$ El desafio institucional pudo ser bastante atrevido, aunque siempre se mantuvo dentro de los parámetros legales y espirituales que todos los actores conocían muy bien. A la religiosa, individualmente, le costaba mucho más angustia espiritual separarse de un confesor o desafiar a un superior, pero aun así, muchas lo llegaron a hacer. Véamos dos casos ocurridos en las primeras décadas del siglo XVIII. En 1716 Sor Gertrudis de San Pedro, del convento de Santa Isabel de México, presentó una vehemente protesta contra su superior, Fr. José Cillero, provincial de la orden franciscana, acusándolo de haberla desposeído del oficio de abadesa, para el cual había sido canónicamente electa, y haberla sustituida con otra, ordenándolo todo bajo "precepto de santa obediencia". De este proceso legal se siguieron otros incidentes como la deposición del padre Cillero por el Comisario General y una protesta de las religiosas del convento de Santa Clara para que se repusiera al padre Cillero, lo que obligó a visitas del arzobispo Lanciego y Eguilaz (1714-1728) y del virrey, y la intervención de la Audiencia para calmar los ánimos de las monjas, quienes obviamente no favorecían a su hermana en religión. Durante el proceso, el arzobispo de México criticó abiertamente a los franciscanos, expresando que el convento ardía en discordias y facciones. ${ }^{25}$

En 1721 la priora electa de Santa Teresa la Nueva, Sor Juana María de San Esteban, rechazó las enmiendas dadas por el arzobispo a su lista de oficios en el convento. Intolerante ante esos cambios, Sor Juana María ofreció su renuncia si el arzobispo no accedía a dejar a las que ella había nombrado. El arzobispo no sólo la relevó de su cargo, sino que, habiendo ella sido obligada por las circunstancias a firmar algunos papeles para mantener

\footnotetext{
${ }^{23}$ A pesar de mostrar comprensión de los problemas de su época Palafox elaboró reglas para varios conventos de Puebla que no se separaban en nada de la más perfecta ortodoxia.

${ }^{24}$ AGN, Inquisición, Vol. 610, exp. 8 (1667). Aquí una religiosa declaró haberse separado de un confesor que le hizo proposiciones deshonestas durante la confesión, y de quien se apartó inmediatamente.

${ }^{25}$ BNFF, Leg 1257, exp. 1262; AGN, México, Clero Regular y Secular, Vol. 160, exp; 2.
} 
los cambios fuera del rumor público, la despojó de su velo por inobediente, condenándola a varios años de cárcel dentro del monasterio de Santa Teresa la Antigua. Habiéndose hecho público el caso, se le dió la oportunidad a la monja de elaborar una defensa jurídica ante la Audiencia. La publicidad obligó al arzobispo a enviarla a Caracas como fundadora de un convento. ${ }^{26}$

Estas desavenencias se nos han ido revelando poco a poco a través de la investigación, y algunas lucen mucho más estridentes que la desavenencia de Sor Juana con el padre Antonio Núñez, que aunque no estudio aquí, no tuvo repercusiones sociales como en los casos anteriores. Ya debajo de esta convicción, deseo revisitar el célebre intercambio entre Sor Juana y el obispo Manuel Fernández de Santa Cruz, y replantearlo dentro del marco de la vida religiosa de su tiempo, partiendo de la premisa de que Sor Juana, como súbdita de sus prelados y como monja, se obligó a obedecer a sus superiores religiosos y aunque no podía legítimamente evadirse de cumplir ese elemento tan esencial a su condición, si podía expresar sus dudas al respecto. Dentro del imperativo de la obediencia, su espíritu forcejeó por vivir su libertad y establecer el respeto de su albedrío intelectual. La batalla fue dura, y el episodio con el obispo es un ejemplo de una realidad que otras monjas también vivieron. Como se ha señalado, hay sutiles diferencias entre la carta de desafio al padre Núñez y la correspondencia con el obispo. La posición tomada por Sor Juana frente a ambos tenía que ser diferente, dado que el obispo no tenía con ella la misma intimidad espiritual que tuvo Núñez. ${ }^{27}$

La relación entre Fernández de Santa Cruz y Sor Juana fue especial en cuanto a que Sor Juana no fue ni hija espiritual ni súbdita del prelado, lo cual le restaba a éste autoridad canónica sobre ella, y le daba a Sor Juana un espacio más amplio para el diálogo intelectual. Sin embargo, la relación entre un príncipe de la Iglesia y una monja, fuera o no súbdita, demandaba el respeto a las jerarquías eclesiásticas y de género características del cristianismo católico. También envolvía el uso de recursos proporcionados por el canon religioso para resolver transgresiones y restañar relaciones. El recurso más ortodoxo del católico que ha roto algún canon de la iglesia, sea desobediencia de los mandamientos éticos, del dogma religioso, o del modo de comportarse dentro de la institución, es el acto de contrición. La contrición es la renuncia del pecado, parte esencial del proceso de retornar a la gracia de Dios. Durante el Alto Medioevo y hasta el Concilio de Trento también se consideró el estado de atrición, que es un estado de pena en el cual la renuncia es menos completa, y parte de un proceso que lleva a la contrición. Uno de los más influyentes teólogos del momento, Duns Scotus, consideró que la atrición era suficiente para justificar el sacramento de la penitencia. El Concilio de Trento (1540-63) definió la atrición como acto volitivo sin afirmar o excluir la evolución de un estado a otro. ${ }^{28}$

\footnotetext{
${ }^{26}$ Alegación Jurídica y manifestación de sus derechos, que para el uso de sus defensas hacer constar su inocencia ha practicado la R.M. María de San Esteban (México, 1728). Sor María de San Esteban declaró haber escrito al obispo "con el amor, respeto y reverencia de hija a padre ..." pero obviamente Fr. Joseph Lanciego y Eguilaz, no toleró la pretensión de su súbdita de que se retractara de sus nombramientos y le diera a ella el derecho de hacer los suyos. Eso significaba sobreponerse a la voluntad del prelado.

${ }^{27}$ Tapia Méndez, Carta de Sor Juana Inés de la Cruz a su confesor, 29-42.

${ }^{28}$ Catholic Encyclopedia (Washington: The Catholic University Press, 1967), 4: 278 y sig. Una característica del pensamiento medieval fue ver la atrición como parte de un proceso que culminaba
} 
Mi tesis es que en la correspondencia entre Fernández de Santa Cruz y Sor Juana hay una mezcla de obediencia y desobediencia, de atrición y de desafío que no debe ignorarse. Esta tensión interna explica mejor la personalidad de Sor Juana como monja del siglo XVII que la interpretación de la religiosa y de estos escritos como ejemplos de airosa rebeldía. La escritura de ambas piezas ha sido ampliamente analizada por muchas plumas y el tono de reconvención del obispo no se le ha escapado a nadie. José Pascual Buxó ha hecho un análisis muy inteligente y bien cimentado de todos los argumentos ofrecidos para explicar el origen del intercambio entre Sor Juana y el obispo y la decisión de entregarse enteramente a la fe. ${ }^{29}$ En un momento se pregunta Buxó si no hubo modo alguno para "reducir al silencio y la obediencia a una monja desmandada ..." Lo cierto es que aunque los hubo, no siempre rindieron efecto, como lo demuestran los casos citados arriba. Y, precisamente, tanto en la Carta atenagórica como en la Respuesta hay elementos de las estrategias desarrolladas por monjas y prelados antes y después de Sor Juana en puntos de disensión, contradicción y solución de problemas de observancia.

Teniendo en cuenta los ejemplos históricos brevemente señalados en este trabajo, cabe ahora subrayar aquellos pasajes en los cuales Sor Juana se expresa como monja debatiéndose entre la obediencia y la libertad. Para comenzar, recordemos que en su Carta atenagórica Sor Juana inicia sus argumentos constatando que fue el deseo del obispo Manuel Fernández de Santa Cruz el resorte que movió la escritura de lo que antes había sido una discusión oral posiblemente llevada a cabo en los locutorios de San Gerónimo. A través de la Carta atenagórica repite constantemente su obediencia religiosa, que aunque no le debía al obispo jurisdiccionalmente, le debía como varón de la Iglesia, ya que así lo establecían los preceptos de la iglesia misma. ${ }^{30}$ Pretende Sor Juana encontrar un territorio neutro en el cual desarrollar su tesis, esto es, ejercer su libertad individual como intérprete de un punto teológico, en la privacidad que esperaba del obispo y su obediencia incondicional de la autoridad de la Iglesia. "Este papel sea tan privado que solo lo escribo porque V.md. lo vea", (758). Arguyó Sor Juana que si escribió y envió al obispo sus argumentos fue porque "nació en V.M. el deseo de ver por escrito ..." sus opiniones sobre el sermón, a cuyo deseo se rinde "porque conozca que le obedezco en lo más difícil" (733) que era la escritura. La oralidad de sus conversaciones le garantizaban una inmunidad que se perdía con la escritura. El escribir significaba dejar evidencia de sus ideas, exponerse a

en la contrición. La controversia sobre estos grados de renuncia al pecado y el error siguió después del Concilio de Trento. Se debatía si la atrición y la contrición eran motivadas por el amor desinteresado a Dios o por miedo al castigo y algunos teólogos se inclinaron a separar la secuencia atrición-contrición.

29 José Pascual Buxó, "Sor Juana: monstruo de su laberinto", en Sara Poot Herrera, editora, $Y$ diversa de mí misma entre vuetas plumas ando: Homenaje internacional a Sor Juana Inés de la Cruz (México: El Colegio de México, 1993), 43-70.

${ }^{30} \mathrm{La}$ autoridad del obispo Manuel Fernández de Santa Cruz estaba bien fundada en 1690 . Fue obispo de Chiapas y Guadalajara antes de ocupar la silla poblana, y había sido designado por Carlos II para reemplazar a Fr. Payo Enríquez de Ribera en el arzobispado de México y la dignidad virreinal, cargos que no aceptó en razón de humildad religiosa. Véase, Francisco Sosa. El episcopado mexicano: biografía de los Illmos. señores Arzobispos de México, 2:209-10. 
la lectura, y con ello quedar sujeta al elogio o a la crítica. De ahí su resistencia a dejar una constancia irrevocable.

Escribir era comprometerse. Pero escribió bajo el supuesto de que si algún error cometía en la interpretación de las escrituras, aceptaría las enmiendas del obispo ("la propia autoridad de su precepto honestara los errores ..., 734). ${ }^{31}$ "He obedecido a V. md. en lo que me mandó" (757), "lo sujeto en todo a la corrección de Nuestra Sagrada Iglesia Católica y detesto y doy por nulo y por no dicho todo aquello que se apartare del común sentir suyo y de los Santos Padres" (758?). No son en modo alguno estas frases huecas de sentido o sentimiento. Obedecían al imperativo post-tridentino de someter toda discusión teológica a la sanción calificadora de quienes estaban autorizados para ello por la Iglesia. En este caso, el obispo asumía la responsabilidad de corregir a quien debía acercarse a una discusión teológica - como cualquier otro miembro de la iglesia - con la renuncia incondicional de su defensa y la aceptación, en los mismos términos, de su posible culpa. Una y otra vez excusa el despulimiento de su tesis, el posible yerro de su posición, comparándose a un pigmeo atreviéndose con Hércules, y cubriéndose bajo la capa de ser instrumento de Dios, aunque, por ser mujer, "flaco instrumento". Era también parte de la mentalidad de la época ver en la mujer a un ser menos perfecto que el hombre, aunque capaz de sobrepasar la cortapisa mujeril. Sor Juana se sabía bien la lección, y no deja de apreciar que Vieyra pudiera sentirse humillado al ser contrariado por una mujer, pero hay ejemplos (los de Judit y Débora) de que Dios ha escogido antes al género femenino para hacer su voluntad, y ella se presta a obedecer basada en ejemplos ortodoxamente aceptables. Todas estas formas de capitatio diminutio no fueron simples formas retóricas de la escritura o juguetes en manos de la inventiva de Sor Juana. Fueron formas de protegerse $a$ priori de cualquier acusación de irreverencia 0 , aún peor, de falta de ortodoxia, y hay que tomarlas seriamente dentro del contexto del siglo XVII. La impresión que dejó el Santo Oficio en la sociedad mexicana de mediados del siglo XVII fue delineada con las sombras de los autos de fe y condena a la hoguera de judaizantes y luteranos, que sólo amainó después de $1650 .^{32}$ Claro que esta situación no afectaba a las ortodoxas monjas novohispanas, cuyos peores pecados contra el dogma católico fueron los de "blasfemar" contra algunos artículos de fe que eran muy remediables dentro de la Iglesia. Pero, no hay duda que el el Santo Oficio era una institución de la cual muchos recelaron justificadamente. ${ }^{33}$

En la Carta atenagórica se ve claramente el punto y contrapunto de la obediencia a la autoridad y la forzosa defensa del libre albedrío, que toma mayor impulso en la Respuesta. Es arropándose en la obediencia que se proteje Sor Juana de su osadía intelectual y teológica. Ella, que reclamaba no atreverse a pisar el terreno de la más alta ciencia, se adentró en el

${ }^{31}$ Utilizo la edición de Georgina Sabat-Rivers y Elías Rivers, Sor Juana Inés de la Cruz: Obras Selectas (Barcelona: Editorial Noguer, S.A., 1976).

${ }^{32}$ Tanto judaizantes como homosexuales y protestantes murieron en la hoguera hasta la sexta década del siglo XVII. Véanse, Seymour B. Liebman, The Jews in New Spain (Coral Gables: University of Miami Press, 1970); AGI, Inquisición, Vol. 718, exp. 11 (1701); Serge Gruzinski, "Las cenizas del deseo. Homosexuales novohispanos a mediados del siglo XVII", en Sergi Ortega, ed. De la santidad a la perversión (Mexico: Grijalbo, 1985), 255-81.

${ }^{33}$ Véanse, AGN, Inquisición, vol. 278, exp. 6; Vol. 284, exp. 72, Vol. 718, exp. 10, Vol. 722, fols 369-402. 
mismo con singular fuerza intelectual, pero consciente de que había arenas movedizas bajo sus pies. En el segundo acto de la correspondencia, la Carta de Sor Filotea de la Cruz (Obispo Manuel Fernández de Santa Cruz) a Sor Juana, se desarrolla la respuesta episcopal. Hay una gran dosis de admonición pastoral, rayana con impaciencia, que logra organizarse a través del canon de la obediencia. El obispo comienza negando como "vulgaridad" unirse a aquéllos que reprochan a las mujeres el uso de las letras, descartando cualquier sospecha de estrechez intelectual ante el revuelo ocasionado (al parecer) por la carta. No podía hacerlo como miembro de una religión que instaba a las profesas a escribir, y menos dirigiéndose a una religiosa perteneciente a una orden monástica que se preciaba de su intelectualidad. Sin embargo, recordemos que la constante presión de confesores instando a las religiosas a escribir estaba orientada en gran parte a escrutinar la ortodoxia de su fe, especialmente desde el último cuarto del siglo XVI ${ }^{34}$ Es posible que las críticas y las defensas que Sor Juana menciona en su Respuesta hayan movido al obispo a tomar una posición "correcta" en su relación con la monja después de la publicación de la Carta atenagórica. En la Carta de Sor Filotea, el obispo retornó a su misión de director espiritual y consejero de ortodoxia.

Para Fernández de Santa Cruz la escritura de la mujer no debía conducir a vanidad, una de las reconocidas flaquezas de su sexo. Implícitamente le echaba a la cara a Sor Juana el haber sido vanidosa. Siguió hundiendo la hoja de su cuchillo recordándole los conceptos de sumisión a la autoridad y obediencia, que en ella se combinaban por ser mujer y monja. La sumisión de la mujer al hombre existió desde la primera palabra de Dios en el Antiguo Testamento. ${ }^{35}$ La súbdita en casa de Abraham no debía hacerse ilusiones de autoridad. La escritura tiene un fin santo y "no las reprueba el apóstol cuando no sacan a la mujer del estado obediente". Elogia el cautiverio de Sor Juana a las letras, pero sólo para recordarle que tiene ella el poder (el libre albedrío y la capacidad volitiva) de rendir esa obediencia a otras letras de fines superiores. La insta a considerar que ya es tiempo de abandonar los intereses mundanos. Era 1690 y Sor Juana tenía cerca de cuarenta años. Había gastado ya mucho tiempo en estudios de filósofos y poetas y era hora de perfección en "los empleos y que se mejoren los libros" (766). El obispo le sugiere un holocausto mayor que el que ha llevado a cabo: que encadene su entendimiento al único verdadero conocimiento, el de Dios. Al recordarle cómo Dios criticó a José y otros eruditos que se vieron engañados por el conocimiento de las letras humanas, le reprochó que se hubiera dejado llevar por el vicio de la curiosidad, instándole a la virtud del estudio de la filosofía moral.

El tono de su carta va pasando gradualmente de elogio a crítica. Todos sus sus consejos estan dados imperativamente, haciéndose más ácidos a medida que avanza. Al final, asestó el golpe más duro: la crítica de los argumentos teológicos de Sor Juana sobre la mayor fineza de Dios. Decía Sor Juana que Dios quiere nuestro amor para nuestro bien, no para el suyo (754-57). Actuando bajo ese concepto, Dios a veces nos deja de hacer favores para

\footnotetext{
${ }^{34}$ Álvaro Huerga, Historia de los alumbrados Vol. 3, "Los alumbrados de Hispanoamérica (15701605)". (Madrid: Fundación Universitaria Española, 1986).

${ }^{35}$ Rosemary R. Ruether, ed. Religion and Sexism: Images of Women in the Jewish and Christian Traditions (New York: Simon and Schuster, 1974).
} 
que no podamos pagarle con nuestra ingratitud. Dios demuestra su amor reprimiendo "los raudales de su inmensa liberalidad; detiene el mar de su infinito amor y estanca el curso de su absoluto poder" (759). Era una curiosa interpretación barroca con ecos de retruécano teológico, que Fernández Santa Cruz negó firmemente. Dios no necesita reprimir sus beneficios. Los da con liberalidad para que sean reconocidos y más abundantes. Si Dios siguiese la lógica de Sor Juana, se vería obligado a parar esos raudales de liberalidad para con ella, quien parecía sólo pagarle con su ingratitud en no reconocer tales beneficios. Lo que Sor Juana llama "finezas" eran en buena teología "castigos". Dios es omnipotente y le debe el hombre el agradecimiento por su gracia ya que de esa gracia depende la capacidad humana de reconocer que la liberalidad divina no se puede reprimir y se expresa con mayores liberalidades cuanto más se la reconoce y agradece. Sin necesidad de la presencia de la Inquisición, la problemática del error interpretativo en cuestiones de dogma requería la corrección del prelado y la renuncia por parte de la creyente. Esa renuncia podía ir envuelta en un acto de atrición. La contrición no creo fuera requerida en la situación de Sor Juana, en cuanto a que no había incurrido en ningún pecado o blasfemia al dar su opinión sobre Vieyra. Pero sí había mal-interpretado la naturaleza del amor de Dios. Fernández de Santa Cruz pone a la monja en "su lugar", como lo haría cualquier confesor reprimiendo a una hija espiritual desviada en su interpretación. Se despide Fernández de Santa Cruz reiterándole la admiración de su alma y su amor, pero pidiendo a Dios que "la haga muy santa", o sea, que le cambie el rumbo de su vida (768).

El obispo de Puebla era un pastor de almas. Admiraba a Sor Juana, pero más allá de su interés en leer sus ideas teológicas y de admirar su genio, se vió obligado a ejercer su autoridad episcopal para corregirla y tratar de llevarla al buen camino de la religión. ¿Qué tipo de prelado era Manuel Fernández de Santa Cruz? Dejando de lado los panegíricos póstumos de su perfección religiosa, algunas de sus actividades lo pintan como un prelado muy interesado en la protección y "recogimiento" de la mujer en general, y muy limosnero respecto a los conventos de religiosas. Fernández de Santa Cruz pudo haber sido arzobispo de México, pero declinó el cargo, lo que indica que ejerció un singular control sobre su ambición de poder personal. Prestó su apoyo a la fundación del convento de agustinas recoletas de Santa Mónica, subsidió varias escuelas de niñas doncellas y se preocupó mucho por mantenerlas económicamente viables. Su apoyo a un proyecto de fundación de un convento de capuchinas en la ciudad se vió frustrado durante el resto de su vida, pero no cejó en su intento habiendo prometido parte de su caudal. Fue también uno de los más dedicados promotores de la causa de la beatificación de Sor María de Jesús Tomellín, religiosa del convento de La Concepción en Puebla, que murió en 1637 bajo reputación de mística visionaria, y en olor de santidad. ${ }^{36}$

\footnotetext{
${ }^{36}$ AGI, México, Leg. 829, (1696-1724). Expediente de los bienes que dejó Da. Ana de Zúniga para la fundación de dos conventos de monjas en la Puebla de los Ángeles: uno de capuchinas y otro de mercedarios; Félix de Jesús María, Vida y virtudes, y dones sobrenaturales de la Ven. Sierva de Dios, Sor María de Jesús, religiosa profesa en el V. monasterio de la Inmaculada Concepción de la Puebla de los Angeles en las Indias Occidentales (Roma, 1756), 349. El proceso de beatificación fue iniciado por el obispo Palafox y continuado por Diego Osorio y Escobar y Manuel Fernández Santa Cruz. Este último hizo un cuestionario con 146 testigos que fue enviado a Roma en 1695.
} 
En cuanto a sus relaciones personales con varias religiosas hay anécdotas que lo pintan muy voluntarioso, amigo de la obediencia de sus súbditas, aunque también muy devoto de las que consideró "ejemplares". Los historiadores del convento de carmelitas descalzas de Puebla, José Gómez de la Parra y su primo José Martínez de la Parra, nos presentan al obispo en una serie de curiosos vignettes que lo muestran patrono de este convento y ejerciendo su ministerio con firmeza. Con las teresas estuvo siempre bien dispuesto. Por ejemplo, en 1678 dispensó la edad a una novicia de 43 años, Sor Antonia del Espíritu Santo, por favorecer su entrada a la religión a quien era viuda y vió morir a sus tres hijos. Después insistió en que fuera de prelada fundadora a Guadalajara, "bajo precepto de obediencia", y logró su aspiración a pesar de haber sufrido la monja un accidente. En 1678 dió la licencia para que se diera el hábito antes de su muerte a la donada negra Esperanza de San Alberto. También apreciaba ligerezas de vez en cuando, como en la ocasión que llegando al torno de las carmelitas sin ser anunciado saludó a la madre Leonor de San José con "voces mexicanas" para despistarla. Dos carmelitas tuvieron visiones respecto a la muerte del obispo. ${ }^{37}$ Fernández de Santa Cruz sabía también de guardar rencores. Queriendo ayudar a doña Antonia de Berrueco, viuda con siete hijas, procuró aviarle la dote a una a través de una obra pía. La misma fue la madre Leonor de San José, quien profesó en las carmelitas. Pero habiendo ofrecido poner a las otras seis hermanas en uno de los colegios que fundó para doncellas pobres, fue rechazado por Tomás Palacio, el único hijo de la familia, quien por orgullo se negó a la ayuda, y empeoró la situación al criticar al obispo los planes para la fundación de las agustinas recoletas de Santa Mónica. Jamás volvió Fernández de Santa Cruz a dirigirle la palabra. Aunque el obispo sacó a otra hija de la familia para colocarla en un colegio y finalmente en San Gerónimo, su actitud para la tercera aspirante, Juana, quien había de ser Sor María de San José, fue intempestiva y hasta grosera. Bajo la influencia de su confesor, quien medió a favor de la aspirante, el obispo le concedió lugar en Santa Mónica y después llegó a apreciarla tanto que la envió de fundadora a Oaxaca. ${ }^{38}$ Sus actividades no dejan lugar a dudas de que se consideraba un protector de la mujer, pero es también innegable que su visión de la mujer reflejaba la de su tiempo: las doncellas para ser guardadas, las beatas para ser protegidas, y las monjas para dedicarse a la religión y usar sus luces en el elogio y encomio de Dios. Y todas, como mujeres, obedientes. Fernández de Santa Cruz no tenía jurisdicción para hacer a Sor Juana obediente, pero sí la tenía para reconvenirla y aconsejarla. Su relación con la monja ha sido interpretada diversamente como la de amigo y enemigo, pero quizás la verdad se encuentre en el medio aúreo: pastor impresionado por su genio, pero decepcionado por sus lazos con el siglo.

${ }^{37}$ Gómez de la Parra, Fundación y primer siglo, 317, 335, 349-53, 370.

${ }^{38}$ Kathleen Myers, ed. Word from New Spain: The Spiritual Autobiography of Madre Maria de San José (1656-1719) (Liverpool: Liverpool University Press, 1993), 82-83, 174-75, 178, 183, y también, "A Glimpse of Family Life in Colonial Mexico: A Nun's Account", Latin American Research Review, 63-87. Véanse también, Fr. Sebastián de Santander y Torre, Vida de la Venerable Madre María de S. Joseph (México, 1723), 113-114, 15; Marie Cécile Bénassy-Berling, "Sobre dos textos del Arzobispo Aguiar y Seijas", en Sara Poot Herrera, ed. Y diversa de mi misma, 85-90. Bénassy se refiere tanto a Fernández de Santa Cruz como a Aguiar y Seijas. 
Hasta aquí el elemento de la autoridad episcopal. Ahora pasemos al tema de la desobediencia dentro de la obediencia. La Respuesta a la muy ilustre Sor Filotea, se ha visto como un canto a la libertad intelectual, un documento de corte feminista con fuertes trazos de rebelión contra la autoridad patriarcal. Sin negar esas características creo que es necesario subrayar los elementos de subordinación que la obediencia conventual impuso a Sor Juana y a la cual, aun en lucha con su propio espíritu, le convenía someterse, siquiera por seguir la rebelión dentro de los límites dentro de los cuales le era permitido. ${ }^{39}$

De entrada, Sor Juana se confiesa temerosa de no saber como responder a la carta. Se dice aturdida por el regaño de Santa Cruz y demudada por la revelación de su "ignorancia". Su silencio se debe al pasmo de "no saber nada digno de vos". ¿Ironía, o simple táctica de confesionario para introducir su defensa? Inmediatamente se agarra de un recurso religiosamente ortodoxo: dice ver que la impresión de la carta fue un aviso de Dios, quien, al contrario de lo que ella afirmaba en su Carta atenagórica, no le estaba negando su favor para que ella no transgrediese más, sino que la quería reducir a su obediencia con más beneficios, como le explicó el obispo. Santa Cruz había sido vehículo de Dios, al darle la facultad de obligarla a hacerse su propia juez y reconocer su error. Sor Juana se readjudica su capacidad intelectual y moral al reconocer su propio error, pero no estaba ortodoxamente en ella la capacidad de perdonarse. Dios, dice Sor Juana, la ha librado del último castigo (su condena por sí misma) y la ha ayudado a librarse de su propia ignorancia con su misericordia, esa "fineza" que ella le negaba y el obispo reafirmaba. El amor de Dios no se expresa en reprimir sus favores sino en dar más amor. Sor Juana ha capitulado. Acepta el canon de su iglesia.

Si analizamos cuidadosamente los primeros cinco párrafos de la Respuesta nos damos cuenta que resumen una completa renuncia de su interpretación de Vieyra y los atentados de interpretación teológica de Sor Juana. Se humilla al quitarse toda traza de autoridad apoyándose en su sexo, su edad (aún no lo suficiente madura para las profundidades teológicas) y "las costumbres" de que las mujeres no traspasaran terrenos prohibidos. Por suerte, sus errores en los asuntos profanos no la deprivan de "comulgar y oir misa", esto es, de mantener su ortodoxia religiosa, lo que parece importarle mucho. Cualquier yerro contra la ortodoxia religiosa basado en su falta de preparación en ese terreno, dice, pudiera meterla en aguas profundas con la Inquisición, y esta idea es suficiente para apartarla de cualquier torcimiento del dogma. ${ }^{40}$

Tras de esta aceptación de su derrota teológica, Sor Juana reafirma su intelecto y su personalidad, pero sin desobedecer. Se declara recipiente en obediencia de la amonestación,

\footnotetext{
${ }^{39}$ Cabe recordar aquí el caso de Ana de San Bartolomé, cuya habilidad para sobrevivir los conflictos de autoridad con sus superiores pueden haber sido modelos para otras. Ver, Electa Arenal y Stacey Schlau, Untold Sisters: Hispanic Nuns in Their Own Works (Albuquerque: University of New Mexico Press, 1989) 34; Amanda Powell, "Women's Reasons", 61.

${ }^{40} \mathrm{La}$ revisión de los casos inquisitiorales levantados a monjas de su tiempo revelan cuán lejos estaba Sor Juana de caer en ninguna transgresión, aunque puede haberle inquietado la idea como a cualquiera otra monja. Exagera para recalcar el arrepentimiento demandado de su obediencia. Véase, María Agueda Méndez et al. Catálogo de textos marginados novohispanos. Inquisición: Siglos XVIII y $X I X$ (México: Archivo general de la Nación, El Colegio de Mexico y Universidad Nacional Autónoma, 1991), 19, 103, 119-130, 342.
} 
pasando a interpretar la reprimenda como permiso para hablarle de su inhibición ante la majestad de las sagradas letras y, usando de su libre albedrío, explicar al obispo la raíz de su error. Es de ahí en adelante que arranca su propia defensa con la historia de su vida, que se puede ver como una confesión entrelazada a un acto de atrición, elementos necesarios en toda confesión de error, y eventual reconciliación del cristiano con Dios (774). A través del resto de la Respuesta se nota la preocupación por demostrar que sus estudios se orientaban a alcanzar la teología (777), aunque su aspiración se recrea en los meandros de otras ciencias que, últimamente, la llevarán a su destino final. Gran parte del cuerpo central de la Respuesta desarrolla una parábola entre la vida de Cristo y las de otros que igualmente se señalan, como ella, un recurso que juzgo añade fuerza, de modo oblicuo, a su doble posición de penitente y auto-defensora.

Sor Juana se mueve entre la aserción de la libertad y la reiteración de la obediencia para al cabo abocarse a la pregunta clave: ¿es lícito o no a las mujeres estudiar teología? $\mathrm{Si}$ "Sor Filotea" la insta a los estudios religiosos, era necesario debatir esta cuestión. De nuevo resurge la llama del libre albedrío en su espíritu reclamando la capacidad y libertad para su sexo y haciendo fina burla de la necedad de muchos hombres presuntamente sabios. Aún dentro de un acto de reconciliación con la autoridad episcopal, Sor Juana se tiene que morder la lengua. Llega a los límites permisibles dentro de la obediencia en su propia defensa, pero la reitera pidiendo al obispo que rompa o borre lo que ha escrito, la reprenda si es necesario, y excuse las faltas de la carta $(796,804)$. La Respuesta es un debate desgarrador entre su reclamo de libertad intelectual y la obediencia a la autoridad. En un momento se rebela abiertamente contra sus detractores, $(801,805)$ y defiende su Carta atenagórica con el brío de la pasión que ha estado reprimiendo a través del texto, aunque sólo para desistir de su ira y terminar con una renuncia de las glorias humanas, lección que dice haber aprendido a través de su experiencia con las dos "Cartas". Al cerrar su respuesta ofrece al prelado memoria y copia de sus ejercicios devotos, prometiendo remitirle lo que haga en el futuro, y esperando la liberalidad y beneficios del obispo, a quien se refiere como su deudor generoso. El acto de atrición, tras el emocional debate consigo misma y con su sociedad, ha terminado. ${ }^{41}$ José Pascual Buxó ofrece una muy aceptable explicación de la progresiva evolución de Sor Juana hacia el abandono de las letras y el retorno a lo que era su "estado". Comparto su opinión, que ha sido mía también aunque nunca tan bien explicada. De esta inicial atrición Sor Juana evoluciona hasta la contrición, la renuncia total de su mundanidad varios años después, en un proceso que encaja con la interpretación tomista de estos conceptos aún imperantes en su tiempo.

Mi aportación aquí consiste en proveer datos históricos que hagan la tesis de una Sor Juana mujer y monja más congruentes con su tiempo. El examen de la tensión que marcaban las relaciones entre prelados y súbditas nos muestra un constante diálogo entre la autoridad y la obediencia, la observancia de los cánones de la religión y el vuelo del intelecto, en la

\footnotetext{
${ }^{41}$ Desde luego, la finísima ironía de recordarle al obispo que lo ha tratado como una religiosa por seguir las reglas del juego que él mismo estableció es, a mi ver, una forma un poco socarrona de reiterar su obediencia - llega de nuevo a los límites permisibles de desobediencia- pues es obvio a través de su respuesta que sabe quién es Sor Filotea y se dirije a Su Reverancia, el obispo. Si Sor Juana hubiera sido más rebelde no hubiera repetido tanto el concepto de obediencia.
} 
experiencia personal e institucional. El caso de Sor Juana no fue único. Muchas otras voluntades religiosas, masculinas y femeninas, se debatieron entre los polos del deber, la humildad y la obediencia, y el libre albedrío. En su relación con el obispo Manuel Fernández de Santa Cruz, Sor Juana no pudo librarse de la realidad de ser una monja entre otras ellas, a pesar del amplio vuelo de su intelecto. En esa tensión entre la obediencia a la autoridad y la libertad personal residió quizás su mayor tormento y su mayor gloria. 